\title{
Effects of an educational program focused on self-care and concurrent physical training on glycemia and drug treatment of patients with diabetes mellitus
}

\author{
Silva Junior $\mathrm{AJ}^{1}$ and Gomes $\mathrm{LC}^{2 *}$ \\ ${ }^{1}$ Physical educator, $\mathrm{PhD}$ in Motor Science, Professor and coordinator of the undergraduate course in Physical Education at the University Centre of the Guaxupe \\ Educational Foundation (UNIFEG) Guaxupe, Minas Gerais, Brazil \\ ${ }^{2}$ Nurse $\mathrm{PhD}$ in Sciences, Professor and coordinator of the undergraduate course in Nursing at the University Center of the Guaxupe Educational Foundation \\ (UNIFEG) Guaxupe, Minas Gerais, Brazil
}

\begin{abstract}
Diabetes mellitus requires clinical care and continuing education for the prevention of acute and chronic complications. The literature shows that educational interventions can promote, among other benefits, the reduction of the glycemic level, especially when they include, in practice, the changes of lifestyle. The present study aimed to evaluate the effects of an educational program, focused on self-care and concurrent physical training on glycemia and drug treatment in 15 diabetic patients. There was a higher frequency of female patients, in the sixth decade of life with a low level of schooling, a diagnosis time of less than 10 years, and the use of oral antidiabetics. It was observed a significant reduction of glycemic level $(-58.1 \mathrm{mg} / \mathrm{dL}$, p-value $=0.010)$ between the time of the study (T0 and T4), as well as the number of tablets of the main drugs prescribed: glibenclamide ${ }^{\circledast}(\mathrm{p}<0.005)$ and metformin ${ }^{\oplus}(\mathrm{p}<0.001)$, suggesting the existence of physiological adaptations induced by training. It is concluded that the proposed educational program, by including the regular and well-oriented practice of concurrent physical exercise, contributed to self-care and consequently to glycemic control in the sample studied.
\end{abstract}

\section{Introduction}

The diabetes mellitus (DM) is considered an important global health issue, both due to its epidemic proportions [1] and the burden of disease attributable to it [2]. The estimated global prevalence in 2011 was 366 million people affected, with projection to reach 552 million individuals in 2030. It is estimated that between 2011 and 2030, there will be a $92 \%$ increase in the number of people with DM in low-income countries, followed by middle-low-income countries (57\%), middlehigh income countries (46\%) and finally upper-income countries (25\%) [3].

In Brazil, a recent study aimed at identifying the self-reported prevalence of DM in the adult population revealed a prevalence of $7.5 \%$ [4]. Regarding the disease burden attributable to DM, another recent Brazilian study showed that DM represents $5 \%$ of the disease burden in the country [2]. In this context, DM is touted as one of the priority noncommunicable chronic diseases in the formulation of health policies for its prevention, monitoring and treatment of its complications [5] 2011, which should include educational interventions at different levels of health care [6].

Education is considered a fundamental element in the care of the person with DM $[7,8]$ since it is a strategy that can facilitate the person's responsibility and decision making for self-care, as well as promote their autonomy and motivation to use knowledge and skills in solving problems, especially with regard to the prevention of complications [911].

The literature has evidenced the benefits of educational interventions on the glycemic control of people with DM [12-14] and although there is no "gold standard" approach or education program [7] the documents National Standards for Diabetes Self-Management Education and National Standards for Diabetes Self-Management Education and Support propose evidence-based standards to guide DM education programs, which include, among others, a description of the disease process and treatment modalities, practice of lifestyleintegrated physical activity, and monitoring of blood glucose and of other parameters, its interpretation and use of the results for the decision making to self-management.

The evaluation of an educational program should focus on the results to be obtained, which range from the improvement of people's knowledge about the disease, to cognitive-behavioural changes up to the adoption of a healthy lifestyle and their consequential effects on the glycemic profile and in drug therapy [1]. Thus, the present study aimed to evaluate the effects of an educational program focused on self-care and concurrent physical training on glycemia and drug treatment of patients with DM.

*Correspondence to: Lilian Cristiane Gomes, Nurse, PhD in Sciences, Professor and coordinator of the undergraduate course in Nursing at the University Center of the Guaxupe Educational Foundation (UNIFEG) Guaxupe, Minas Gerais, Brazil, E-mail: liliancristianegomes@yahoo.com.br

Key words: diabetes mellitus, health education, self-care, physiological adaptations, physical training

Received: December 15, 2018; Accepted: December 29 , 2018; Published: January 04, 2019 


\section{Materials and methods}

\section{Design and ethical aspects}

It is an intervention study, quantitative approach, with a single comparison group for the analysis of "before and after" results [15] referring to educational program (EP) for people with DM centred on the self-care and concurrent physical training (Figure 1).

This study was developed at the Centre for the Study of Health and Physical Education (CESEF) of the University Centre of the Guaxupe Educational Foundation (UNIFEG) during the period from August to December 2017 and it is part of the matrix project entitled "Evaluation of a program educational program (EP) for people with type 2 diabetes mellitus, with a focus on physical activity and foot care", approved by the Research Ethics Committee of the UNIFEG, dated n. 2,029,352, May 3, 2017.

\section{The study sample}

The base population was made up of people with medical diagnosis of DM2, regardless of the time of illness, not hospitalized and in outpatient follow-up. The invitation to the study was carried out in public health services and the local media. For the sample selection, the following inclusion/exclusion criteria were considered:

Inclusion criteria: People of both sexes, at least 40 years old, sedentary or not active, without advanced complications, whose drug treatment included the use of oral antidiabetic agents (OADs) and/or insulin, and who were able to maintain dialogue.

Exclusion criteria: People with DM2 who had at least one of the following conditions were excluded on hemodialysis, amaurosis, presence of sequelae of stroke, cardiac insufficiency, previous amputations at any level of the lower limb, injury or ulcer active in lower limbs, presence of any other incapacitating complication, use of wheelchair and/or stretcher, inability to communicate verbal, and participants in a physical training program in another institution.

Thus, the sample was initially composed of 19 people with DM2 that met the inclusion criteria and attended voluntarily at the place of study. After being informed about the objectives and procedures of the study including the need for a medical certificate for the practice of physical exercises, the Free and Informed Consent Form (ICF) was provided for reading and signing. However, four participants dropped out due to lack of interest and/or time to attend physical training sessions.

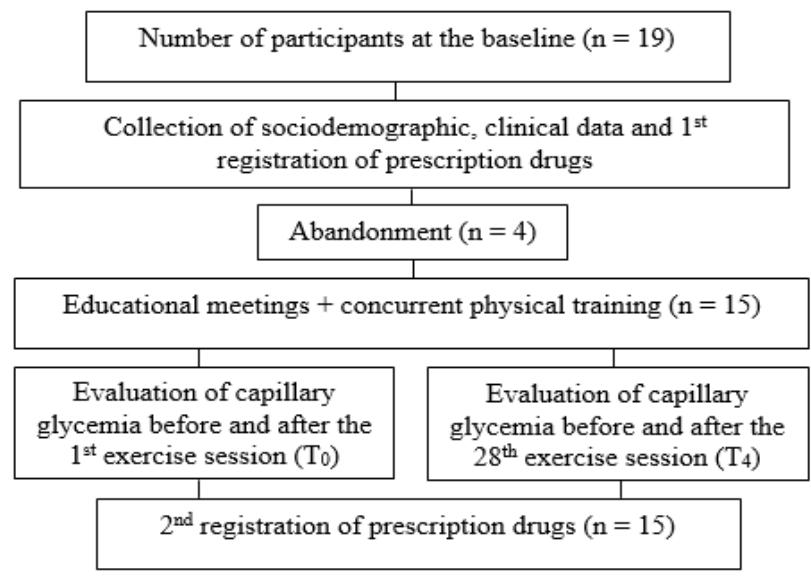

Figure 1. Scheme of the study

\section{Data collection}

After signing the ICF, the sociodemographic and clinical data were collected in a private room, in the form of an individual interview, with an average time of 30 minutes. All participants were asked for the prescription of drugs for the control of the disease, before beginning and after the end of the study interventions. Data on the drug class and daily dosage were recorded in the individual physical training sheets, as well as the capillary glycemia values obtained through digital puncture with standardized equipment and technique, pre and post first $\left(\mathrm{T}_{0}\right)$ and pre and post the last exercise session $\left(\mathrm{T}_{4}\right)$.

It should be noted that the analysis of glycemic control through capillary glycemia was due to the following reasons, low cost and easy access, availability of equipment and supplies at the place of study, obtaining immediate results, and as a motivational factor for the participants' adherence to the study by enabling the practical assessment of the effects of interventions, especially of physical exercises.

\section{Study interventions}

The EP was developed individually in a private room in the premises of the study area by scheduling in common agreement and through nursing consultations, with a properly trained professional. The frequency of the meetings was in accordance with the individual needs of each participant as to the topics discussed, conducted faceto-face and dialogically, in a collaborative approach, with an average duration of 50 minutes and a maximum periodicity of 30 days.

Illustrative posters, prepared by the researchers themselves were used containing public domain images related to general disease management and self-care. The educational material was based on the literature and included the following topics: description of the disease process and treatment modalities; practice of physical activity integrated with lifestyle; glucose monitoring and interpretation; control of body weight; appropriate use of medicines and prevention of complications.

The EP also included 28 sessions of physical training for which methodology of concurrent training characterized by aerobic physical exercises in combination with anaerobic or resisted physical exercises was adopted. The aerobic exercises consisted of three weekly sessions of elliptical, treadmill and bicycle, lasting 30 minutes. The resisted exercises were applied to the upper and lower limbs, with three sets of 12 repetitions, also in three weekly sessions with 30 minutes duration.

All exercise sessions were held in a fully equipped gym, in the premises of the study, and with the direct supervision of physical education professionals. It should be noted that the individual education meetings took place in parallel with the concurrent physical training sessions which were developed in small groups of three to five people, during the four-month period.

\section{Statistical analysis}

The data collected was double typed in MS-Excel application and then processed electronically for validation. Subsequently, the data was exported to the GraphPad InStat software version 3.10 (public domain). The sociodemographic and clinical variables were submitted to descriptive statistics for the characterization of the sample. Numerical data on capillary glycemia and drug dosage (number of tablets per day) were submitted to the Komolgorow-Smirnov and Levene tests, respectively, to verify the normal distribution and homogeneity of the variances. 

diabetes mellitus

For comparisons between two dependent samples (evaluation before and after the development of the EP with physical training) we used the t-test paired, since it showed the normal distribution. The results were expressed as mean and standard deviation with a level of significance $(\mathrm{p})$ less than 0.05 .

\section{Results}

\section{Sociodemographic and clinical characterization of the sample}

The sample was consisted of $73.3 \%$ of female people; mean age of 63 years (standard deviation - SD =7); average schooling time of 5.8 years $(\mathrm{SD}=5.6)$; mean time of diagnosis of 8.9 years $(\mathrm{SD}=$ 7.6); presence of overweight/obesity; use of OADs as prescribed medication treatment $(86.7 \%)$; absence of prior participation in diabetes counselling groups (100\%); and sedentary (73.3\%) (Table 1).

For capillary glycemia, two moments (pre and post) were considered in the first (T0) and in the last session (T4) of physical training, whose mean values and standard deviations were, respectively: T0: $205.5 \mathrm{mg} / \mathrm{dl}=86.7)$ and $174.3 \mathrm{mg} / \mathrm{dl}(\mathrm{SD}=73.6)$; $\mathrm{T} 4: 143.3 \mathrm{mg} / \mathrm{dl}(\mathrm{SD}=28.1)$ and $116.2 \mathrm{mg} / \mathrm{dl}(\mathrm{SD}=16.3)$. There was no statistically significant difference in the evaluation between the two moments of the first exercise session (pre and post $=\mathrm{T} 0$ ), although the mean reduction of $31.2 \mathrm{mg} / \mathrm{dl}$ ( $\mathrm{p}$-value $=0,321$ ) in a single session clinical relevance. On the other hand, there was a statistically significant reduction $(-27.1 \mathrm{mg} / \mathrm{dl}$, p-value $=0.003)$ between the two moments of the last exercise session (pre and post $=\mathrm{T} 4$ ), as well as in the evaluation between the pre-first and pre-last $(-52.2 \mathrm{mg} / \mathrm{dL}$, $\mathrm{p}$-value $=0.043)$, and post-first and post-last sessions $(-58.1 \mathrm{mg} / \mathrm{dL}$; $\mathrm{p}$-value $=0.010)($ Figure 2$)$.

Table 1. Sociodemographic and clinical characteristics of the sample studied. Guaxupé, MG, Brazil, 2018

\begin{tabular}{|l|c|c|}
\hline Variables (n= 15) & n (\%) & Average (Sd *) \\
\hline Sex & & \\
\hline Female & $11(73,3)$ & \\
\hline Male & $4(26,7)$ & \\
\hline Age & & $63(7)$ \\
\hline Women & & $63,4(9,6)$ \\
\hline Men & & $8,9(7,6)$ \\
\hline School time (in years) & & \\
\hline Marital status & $1(6,7)$ & \\
\hline Single & $11(73,3)$ & \\
\hline Married & $3(20)$ & \\
\hline Widower & & \\
\hline Occupation & $4(26,7)$ & \\
\hline Retired with remunerated activity & $3(20)$ & \\
\hline Retired/pensioner & $8(53,3)$ & \\
\hline Work at home, no pay & & $8,9(7,6)$ \\
\hline Time of diagnosis (in years) & & $30,4(5,9)$ \\
\hline Body mass index (BMI) & & \\
\hline Drug treatment of diabetes & $11(73.3)$ & \\
\hline Only oral antidiabetic (OAD) & & \\
\hline Associations (OAD + insulin) & & \\
\hline Prior participation in group guidance on diabetes & & \\
\hline No & & \\
\hline Regular physical activity & & \\
\hline None (sedentary) & & \\
\hline Walk (little) & & \\
\hline & & \\
\hline
\end{tabular}

* $\mathrm{SD}=$ standard deviation

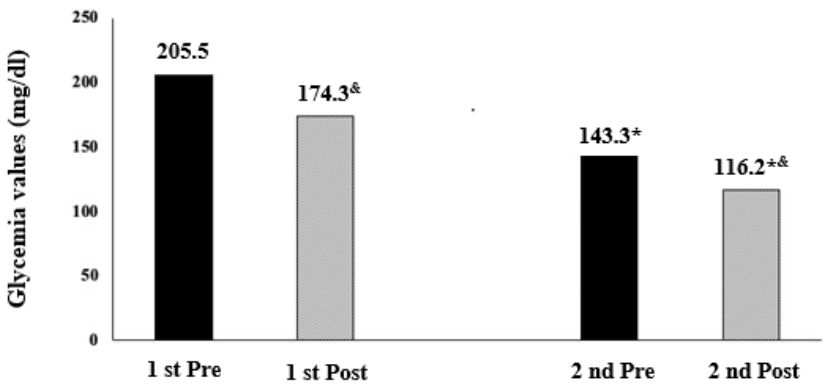

Figure 2. Mean values of capillary glycemia before and after concurrent training sessions * Difference 2nd Pre x 2nd Post; \& Difference 1st Post x 2nd Post ( $\mathrm{p}<0.05)$ Source: Own (2018)

Regarding drug therapy in the comparison between the period prior to EP and the end of this period, there was a significant reduction in the number of tablets of the main drugs prescribed: metformin and glibenclamide (Table 2).

\section{Discussion}

In the sample studied, there was observed a higher frequency of female subjects in the sixth decade of life, with a low level of schooling, a diagnosis time of less than 10 years, the absence of previous participation in educational activities about the disease, presence of overweight/obesity, and in the use of oral antidiabetics. In general, these results resemble those of other studies developed among Brazilian population samples of people with DM [16-19].

The higher frequency of women is consistent with the literature [20-22] and this finding possibly is due to an increased demand and/ or the use of health services by female population [23-25]. In the last decade, the Brazilian studies of prevalence of DM showed divergences as to the association between the disease and the sex. In two studies no statistically significant differences were found $[6,26]$ and in the most recent research there was higher prevalence in women $(8.2 \%)$ than in men $(6.6 \%)(p$-value $=0.001)$ [4] .

Although the low level of schooling is a limiting factor for the teaching-learning process [27] it is believed that the modality of PE proposed in the present study, conducted in order to meet the individual needs of each participant, has contributed to a better understanding of the disease and its management. Thus, education in DM should be a multidisciplinary intervention based on the principles of adult education [28-30] and, particularly for people with low schooling, it should be implemented gradually, continuous and interactive way [31].

Another important aspect to be considered is the fact that the educational meetings were developed individually, not in groups. Some studies have pointed out that the group modality is more advantageous than the individual, especially about your effectiveness in glycemic control $[32,33]$. However, it is reiterated that for the present study, the individual face-to-face modality in a collaborative approach was performed more feasible by allowing a closer contact between professionals and participants, and the latter were able to consolidate their knowledge and clarify your doubts, each at their own pace, without the need to "follow a group". This strategy strengthens the sense of autonomy and empowerment, especially of elderly individuals [17] as it is the case with most of the participants of this study.

About the time of diagnosis, throughout the illness can favour the learning process, since adults and the elderly require self-directed learning, whose essence is their own life experiences [34]. In contrast, 
Silva Junior AJ (2019) Effects of an educational program focused on self-care and concurrent physical training on glycemia and drug treatment of patients with diabetes mellitus

Table 2. Number of tablets of the main drugs prescribed, in the two study times. Guaxupé, MG, Brazil, 2018

\begin{tabular}{|c|c|c|c|}
\hline \multirow[b]{2}{*}{ Drug (concentration) } & \multicolumn{2}{|c|}{ Daily dosage prescribed (number of tablets) } & \multirow[b]{2}{*}{ p- value ${ }^{\#}$} \\
\hline & $\begin{array}{c}\text { Until the beginning of the EP } \\
\text { Average }\left(\mathrm{SD}^{\Phi}\right)\end{array}$ & $\begin{array}{l}\text { At the end of the EP } \\
\text { Average }\left(\mathrm{SD}^{\Phi}\right)\end{array}$ & \\
\hline Glibenclamide ${ }^{\circledR}(5 \mathrm{mg})$ & $2,1(0,7)$ & $0,6(0,5)$ & $<0,005^{*}$ \\
\hline Metformin $®(500 \mathrm{mg})$ & $2,5(0,5)$ & $1,6(0,6)$ & $<0,001^{*}$ \\
\hline
\end{tabular}

$\mathrm{SD}=$ standard deviation

\# t-paired test

*statistical significance

the development of complications and associated comorbidities is more frequent, and may limit access to new information and the incorporation of new habits [17]. In the studied sample, the average time to diagnosis was less than 10 years, considered a facilitating factor for adherence to PE. The recent experience with the DM and its treatment can be the motivation to develop skills and behaviours directed at the control of the disease [35,36].

The fact that all the sample referred to the previous nonparticipation in educational activities about DM suggests a devaluation of the people regarding to this type of activity, and even a difficulty in taking the treatment itself, as well as the lack of incentive or appreciation on the part of health services. Both situations can be a barrier to behavioural change. However, the development of the present study may have supplied this demand and, even so, there were four $(21 \%)$ participants who dropped out during the research. It is widely recognized that DM education is an integral part of disease management $[7,8]$, however, its achievement becomes a challenge in the context of the Brazilian health system, which is still based on prescriptive and curative actions [37]. In addition, depends on the availability of professionals familiar with educational techniques [27] and, especially, the will and the interest of people [38] and those with lower educational levels do not seem to value preventive actions, such as health education [27].

The presence of overweight/obesity is a condition commonly associated with DM2 $[1,6,26]$. The control of body weight falls within one of the American Association of Diabetes Educators (AADE) self-care behavioural patterns ("reduce risks") to guide educational interventions that focus on people's goals [39] and, for this reason it was one of the themes addressed in the EP of this research. The studied sample composed of people who were previously sedentary or not active and considering the physiological changes characteristic of aging and the evolution of DM, the BMI was expected to be above the normality parameter. Studies show that the advancement of age, in addition to possible physical limitations [40] as well as the lack of appropriate locations and/or financial resources for professional supervision are barriers to the practice of physical exercises [41].

It should be stand out the proposed EP included 28 sessions of concurrent physical training, providing free access to equipment and direct supervision of physical educators, besides making it possible to coexist with peers in the small groups. It seems to be a motivational factor for most of the participants stay in the study. A qualitative research approach carried out among elderly women in FlorianópolisSC, Brazil, about the barriers and facilitators to the practice of physical activity, showed that physical exercises appropriate to the clinical conditions and the perception of their benefits in terms of health and quality of life, as well as the company of the pairs and the professional monitoring were fundamental for the adhesion to this behavior of selfcare [40].

Even though it was not the objective of the present study, it should be noted that the BMI suffered a reduction in the mean values (from $32,5 \pm 6,5$ to $30,4 \pm 5,9 \mathrm{~kg} / \mathrm{m} 2$ ), considering the pre and post-intervention moments without statistical significance (data not shown). This fact may have been another motivational factor for the permanence in the study, corroborating the above-mentioned research [40] on the perception of the benefits of physical activities as a facilitator of its practice.

Regarding the drug treatment, the use of ADOs by most participants is coherent to the average time of diagnosis (less than 10 years) and the clinical conditions of overweight/obesity, which insulin resistance is the main etiopathogenic factor and the use of an oral sensitizer agent, in isolation or in combination with another pharmacological class, it assists in the improvement of glycemic control [1]. Other studies developed in Brazilian samples of adults and elderly with DM2, for which the disease time was up to 10 years, the drug therapy resembles that found in this research [19,42-44].

Regarding the effects of the proposed EP on capillary glycemia, no statistically significant difference was observed in the evaluation between the two moments of the first exercise session (pre and post $=\mathrm{T} 0)$, although the mean reduction of $31.2 \mathrm{mg} / \mathrm{dl}(\mathrm{p}=0.321)$, in a single session, has its clinical relevance. On the other hand, there was a statistically significant reduction $(-27.1 \mathrm{mg} / \mathrm{dl}, \mathrm{p}=0.003)$ between the two moments of the last exercise session (pre and post $=\mathrm{T} 4$ ), as well as in the evaluation between pre- $(-52.2 \mathrm{mg} / \mathrm{dL}, \mathrm{p}=0.043)$, and post-first and post-last sessions $(-58.1 \mathrm{mg} / \mathrm{dL}, \mathrm{p}=0.010)$.

These findings suggest that the educational modality adopted, of short-lived, based on the dialogical relationship and collaborative approach, with a view to the individual needs of each participant, was beneficial for the glycemic control of the sample studied. A systematic review aimed to determine the effectiveness of education for the selfmanagement of DM2, showed that the positive effects of educational interventions on the glycemic control were evidenced in studies with a shorter follow-up period (less than six months). It was also observed that the interventions of collaborative approach were more effective to improve glycemic control, than the merely didactic interventions [45]. A study of meta-analysis [46] and other with systematic review [47], with goals similar to the previously cited study, showed that the only variable predictive of improvement in glycemic control was the face-toface education, which corroborates this research.

Other three meta-analyses on the effectiveness of DM education in the improvement of biochemical parameters [48-50], reiterate their positive effects on glycemic control in adults with DM2, when evaluated immediately after the action, similar to the present study. However, the researches reviewed by these authors used the glycated hemoglobin as the only measure of glycemic control, being demonstrated an average reduction that ranged from $0.36 \%[49]$ to $0.80 \%[48,50]$.

Observational study to evaluate the educational activities in promoting self-management of DM2 care in a sample of 27 Brazilian adults affected by the disease, developed analogously to this study in some aspects of the educational modality, as well as the follow-up time, 
Silva Junior AJ (2019) Effects of an educational program focused on self-care and concurrent physical training on glycemia and drug treatment of patients with diabetes mellitus

showed an average reduction of $0.4 \%$ of glycated hemoglobin, but with no statistical significance $(p=0,266)[43]$.

In a study of a "before and after" evaluation, also designed by this research, it was observed a mean reduction of $0.36 \%$ of the glycated hemoglobin between the time of the study $(9.3 \%-8.95 \% ; \mathrm{p}=0.0321)$ in a sample of 82 Brazilians adults with DM2, participants of educational interventions about the disease [51].

A randomized clinical trial involving a Brazilian sample of diabetic adults (intervention group-IG; $\mathrm{n}=38$ and the control group - CG; $\mathrm{n}=38$ ) with the purpose of analysing the effects of an educational intervention on knowledge and biochemical and anthropometric parameters, showed that despite there was no statistically significant difference between the groups, there was a significant difference in intragroup comparisons, that is, between the time of the study (pre and post) in each group. In the CG, there was a mean increase of $0.5 \%$ of glycated hemoglobin and $18.5 \mathrm{mg} / \mathrm{dl}$ of capillary glycemia $(\mathrm{p}=0.001)$ while in the IG there was, respectively, a mean reduction of $2.9 \%$ and $75 \% 3 \mathrm{mg} /$ $\mathrm{dl}(\mathrm{p}=0.001)$ [18] the latter result being similar to the present study.

Another aspect to be considered is that the proposed EP made possible the regular and oriented practice of physical exercises, which also contributed to the reduction of glycemia. The literature establishes that physical exercise induces physiological adaptations that lead to greater sensitivity to insulin and, consequently, to better glycemic control (ARSA et al., 2009). Concurrent physical training contributes to the increase in cardiorespiratory capacity, muscular strength and endurance, which are necessary for the performance of daily life activities and therefore for a better quality of life $[52,53]$.

Two intervention studies also corroborate the findings of the present investigation, although they have employed different training modalities. The first one developed in 13 weeks to verify the effects of aerobic training on blood pressure, BMI and capillary glycemia of 22 Brazilian, diabetic and sedentary elderly women, allocated in two groups (G1: control group, $\mathrm{n}=11$ : educational guidelines, once a week, and G2: intervention group, $n=11$ : aerobic exercises three times a week) did not show a statistically significant difference between the groups in the evaluation of capillary glycemia. However, in the comparison of baseline and final values in both groups, the average reduction of 73 $\mathrm{mg} / \mathrm{dl}$ was observed in $\mathrm{G} 1(\mathrm{p}<0.001)$ and $60.3 \mathrm{mg} / \mathrm{dl}$ in $\mathrm{G} 2(\mathrm{p}<0,01)$ [54].

The second study, carried out in a Brazilian sample of 20 physically inactive, type 2 diabetic men, with a minimum age of 40 years and allocated in two groups (exercised - IG; $\mathrm{n}=10$ and control - CG; $\mathrm{n}=10$ ), in which the objective was to analyse the glycemic reduction caused by high intensity resistance exercise, also showed that although there was no statistically significant difference between the groups, there was a significant reduction in intragroup comparisons, that is, between study times (pre and post). In IG there was an average reduction of $6.7 \mathrm{mg} /$ $\mathrm{dl}(\mathrm{p}<0.001)$ while in CG the mean reduction was $1.3 \mathrm{mg} / \mathrm{dl}(\mathrm{p}>0,05)$ [55].

It highlights that are still few studies on the effects of concurrent physical training on glycemic control and that have used capillary glycemia as a variable outcome in Brazilian population samples with $\mathrm{DM}$, which hindered the comparisons with the present study.

In relation to the effects of this EP on drug therapy, there was observed a significant reduction in the number of tablets of the main drugs prescribed: glibenclamide $(\mathrm{p}<0.005)$ belonging to the sulfonylurea class, and metformin $(\mathrm{p}<0.001)$ belonging to the biguanides class and the reduction of this last drug was more expressive. It is believed that this fact is due to the hypoglycemic effect of physical training caused by increased insulin sensitivity. Another possible explanation would be the reduction of the glycemic level itself, which required adjustments in the pharmacological dosage.

It is important to emphasize that during the educational meetings, relevant aspects of the pharmacological regimen prescribed, including on insulin therapy, were discussed. Regarding the ADOs, special attention was given to the mechanism of action of each drug and the respective time of taking, aiming at safety and maximum therapeutic efficacy.

A review study about interactions between ADOs and foods indicates that, for sulphonylureas, the recommended time for administration is 30 minutes before meals [56] since its mechanism of action is to increase the insulin secretion $[1,56]$ and, in this way the person will get a satisfactory amount of this hormone to reduce glycemia from food [56]. As for biguanides, it is recommended to administer them 15 to 20 minutes after feeding [56] since it reduces the production of hepatic glucose and presents, even if discreetly, a peripheral sensitizing action of insulin receptors $[1,56]$.

A cross-sectional study of 31 Brazilian diabetic adults hospitalized at a medical clinic to identify ADOs showed that $32.2 \%$ of respondents did not know the name of the medication used; $51.6 \%$ took the medication in an inappropriate time and the most had only notions of the mechanism of action of the ADOs prescribed for their treatment [57]. From this shortcoming, it was evidenced the need to include this topic in the EP of the present study.

Although adherence to drug treatment has not been evaluated, it is likely that the guidance provided in the educational sessions have provided a better understanding and stimulated the appropriate use of medications, which may also have contributed to adjustments in dosage.

As limitations of the study, the small sample size and the nonperformance of biochemical analysis (glycated haemoglobin) should be highlighted, not allowing generalizations. In addition the scarcity of studies that used the same modality of EP, in Brazilian population samples, made it difficult to discuss the results.

\section{Conclusion}

It is concluded that the proposed EP by including the regular and well-oriented practice of concurrent physical training, contributed to self-care, especially with regard to changes in lifestyle and drug therapy and consequently, to glycemic control in the sample studied.

It is suggested that other studies, with different designs and larger sample size, are performed in order to obtain more evidence about educational practices in DM, since there is still no "gold standard" of EP.

\section{References}

1. Sociedade Brasileira de Diabetes. Diretrizes da Sociedade Brasileira de Diabetes 2017 2018. Sao Paulo: Editora Clannad; 2017.

2. Costa AF, Flor LS, Campos MR, Oliveira AF, Costa MF, et al. (2017) Burden of type 2 diabetes mellitus in Brazil. Cad Saude Publica 33: e00197915. [Crossref]

3. Whiting DR, Guariguata L, Weil C, Shaw J (2011) IDF diabetes atlas: global estimates of the prevalence of diabetes for 2011 and 2030. Diabetes Res Clin Pract 94: 311-321. [Crossref]

4. Flor LS, Campos MR (2017) The prevalence of diabetes mellitus and its associated factors in the Brazilian adult population: evidence from a population-based survey. Rev Bras Epidemiol 20: 16-29. [Crossref] 
Silva Junior AJ (2019) Effects of an educational program focused on self-care and concurrent physical training on glycemia and drug treatment of patients with diabetes mellitus

5. Schmidt MI, Duncan BB, Silva GA, Menezes AM, Monteiro CA, et al. (2011) Doencas cronicas nao transmissiveis no Brasil: carga e desafios atuais. Lancet Serie Saude no Brasil p. 61-74.

6. Francisco PMSB, Belon AP, Barros MBA, Carandina L, Alves MCGP, et al. (2010) Self-reported diabetes in the elderly: prevalence, associated factors, and control practices. Cad. Saude Publica 26: 175-184. [Crossref]

7. Funnell M, Brown TL, Childs BP, Haas LB, Hosey, et al. (2010) National standards for diabetes self-management education. Diabetes Care 33: S89-S96.

8. Esden JL, Nichols MR (2013) Patient-centred group diabetes care: a practice innovation. Nurse Pract 38: 42-48. [Crossref]

9. Snoek FJ, Visser A (2003) Improving quality of life in diabetes: how effective is education? Patient Educ Couns 51: 1-3. [Crossref]

10. Knight KM, Dornan T, Bundy C (2006) The diabetes educator: trying hard, but must concentrate more on behaviour. Diabet Med 23: 485-501. [Crossref]

11. Beck J, Greenwood DA, Blanton L, Bollinger ST, Butcher MK, et al. (2017) National standards for diabetes self-management education and support. Diabetes Care 43: 449454.

12. Eakin EG, Winkler EA, Dunstan DW, Healy GN, Owen N, et al (2014) Living well with diabetes: 24-month outcomes from a randomized trial of telephone-delivered weight loss and physical activity intervention to improve glycemic control. Diabetes Care 37: 2177-2185. [Crossref]

13. Lynch EB, Liebman R, Ventrelle J, Avery EF, Richardson D (2014) A self-management intervention for African Americans with comorbid diabetes and hypertension: a pilot randomized controlled trial. Prev Chronic Dis 11:1-11. [Crossref]

14. Chrvalaa CA, Sherrb D, Lipmanb RD (2016) Diabetes self-management education for adults with type 2 diabetes mellitus: A systematic review of the effect on glycemic control. Patient Educ. Couns 99: 926-943. [Crossref]

15. Polit DF, Beck CT (2011) Fundamentos de pesquisa em enfermagem: avaliacao de evidEncias para a pratica da enfermagem. 7 ed. Porto Alegre: Artmed.

16. Coelho ACM, Gomes-Villas Boas LC, Gomides DS, Foss-Freitas MC, Pace AE (2015) Self-care activities and their relationship to metabolic and clinical control of people with diabetes mellitus. Texto Contexto Enferm 24: 697-705.

17. Mendes GF, Rezende ALG, Dullius J, Nogueira JAD (2017) Adherence barriers and facilitators to a diabetes education program: the user's point of view. RBAFS 22: 278289.

18. Lima CR, Menezes ICF, Peixoto MRG (2018) Educacao em saude: avaliacao de intervencao educativa com pacientes diabeticos, baseada na teoria social cognitiva. CiEnc. Educ 24: 141-156.

19. Piza LF, Eleoterio BD, Gomes LC (2018) Avaliacao dos pes de idosos com diabetes mellitus: estudo descritivo. Enfermagem Brasil 17: 245-252.

20. Gomes-Villas Boas LC, Santos CB, Foss-Freitas MC, Pace AE (2009) A relacao entre o apoio social e as caracteristicas sociodemograficas das pessoas com diabetes mellitus. $R G E$ 30: 390-396.

21. Ferreira CLRA, Ferreira MG (2009) Epidemiological characteristics of diabetic patients within the public health system: an analysis of the HiperDia system. Arq. Bras. Endocrinol. Metab 53: 80-86.

22. Araujo MF, Araujo TM, Alves Pde J, Veras VS, Zanetti ML, et al. (2013) [Drug use, blood glucose and body mass index in patients with diabetes mellitus]. Rev Bras Enferm 66: 709-714. [Crossref]

23. Travassos C, Viacava F, Pinheiro R, Brito A (2002) Utilization of health care services in Brazil: gender, family characteristics and social status Rev. Panam. Salud Publica 11: $365-373$.

24. Pinheiro RS, Viacava F, Travassos C, Brito AS (2002) Gender, morbidity, access and utilization of health services in Brazil CiEnc. Saude Colet 7: 687-707.

25. Gomes R, Nascimento EF, Araujo FC (2007) Why do men use health services less than women? Explanations by men with low versus higher education. Cad. Saude Publica 23: $565-574$.

26. Moraes AS, Freitas ICM, Gimeno SGA, Mondini L (2006) Diabetes mellitus prevalence and associated factors in adults in Ribeirao Preto, Sao Paulo, Brazil OBEDIARP Project. Cad. Saude Publica 26: 929-941.

27. Pace AE, Ochoa-Vigo K, Caliri MH, Fernandes AP (2006) Knowledge on diabetes mellitus in the self-care process. Rev Lat Am Enfermagem 14: 728-734. [Crossref]
28. Alderson M, Starr L, Grow S, Moreland J (1999) The program for rheumatic independent self-management: a pilot evaluation. Clin. Rheumatol 18: 283-92. [Crossref]

29. Cooper H, Booth K, Fear S, Gill G (2001) Chronic disease patient education: lessons from meta-analyses. Patient Educ Couns 44: 107-117. [Crossref]

30. Barlow J, Wright C, Sheasby J, Turner A, Hainsworth J (2002) Self-management approaches for people with chronic conditions: a review. Patient Educ Couns 48: 177187. [Crossref]

31. Cazarini RP, Zanetti ML, Ribeiro KP, Pace AE, Foss MC (2002) Adherence of people with diabetes mellitus to an educational group: percentage and causes. Medicina 35 $142-150$

32. Torres Hde C, Franco LJ, Stradioto MA, Hortale VA, Schall VT (2009) [Evaluation of group and individual strategies in a diabetes education program]. Rev Saude Publica 43: 291-298. [Crossref]

33. Steinsbekk A, Rygg LO, Lisulo M, Rise MB, Fretheim A (2012) Group based diabetes self-management education compared to routine treatment for people with type 2 diabetes mellitus. A systematic review with meta-analysis. BMC Health Serv Res 213:1-19. [Crossref]

34. Amendola F, Oliveira MAC, Alvarenga, MRM (2011) Influence of social support on the quality of life of family caregivers while caring for people with dependence. Rev Esc. Enferm. USP 2011; 45(4):884-889. [Crossref]

35. Organizacao Mundial da Saude (2003) Cuidados inovadores para condicoes cronicas: componentes estruturais de acao. OMS, Brasilia.

36. Gimenes HT, Zanetti ML, Haas VJ (2009) Factors related to patient adherence to antidiabetic drug therapy. Rev Lat Am Enfermagem 17: 46-51. [Crossref]

37. Malta DC, Merhy EE (2010) O percurso da linha do cuidado sob a perspectiva das doencas cronicas nao transmissiveis. Interface Comun. Saude Educ 14: 593-606.

38. Pereira FRL, Torres HC, Candido NA, Alexandre LR (2009) Promovendo o autocuidado em diabetes na educacao individual e em grupo. CiEnc. Cuid. Saude 8: 594-599.

39. AADE (2008) AADE7 Self-Care Behaviors. Diabetes Educ 34: 445-449. [Crossref]

40. Krug RR, Lopes MA, Mazo GZ (2015) Barriers and facilitators for the practice of physical activity in old and physically inactive women. Rev Bras Med Esporte 21: $57-64$.

41. Bonetti E, Schaly D, Rover C, Fiedler, MM (2012) Atividade fisica em individuos portadores de diabetes mellitus do municipio de Joacaba SC. EvidEncia 12: 41-50.

42. Otero LM, Zanetti ML, Ogrizio MD (2008) Knowledge of diabetic patients about their disease before and after implementing a diabetes education program. Rev. Latino-Am Enfermagem 16: 231-237. [Crossref]

43. Torres Hde C, Pereira FR, Alexandre LR (2011) [Evaluation of the educationa practices in promoting self-management in type 2 diabetes mellitus]. Rev Esc Enferm 45: 1077-1082. [Crossref]

44. Marques MB, da Silva MJ, Coutinho JF, Lopes MV (2013) [Assessment of self-care competence of elderly people with diabetes]. Rev Esc Enferm USP 47: 415-420. [Crossref]

45. Norris SL, Engelgau MM, Narayan, KMV (2001) Effectiveness of self-managemen training in type 2 diabetes. A systematic review of randomized controlled trials. Diabetes Care 24: 561-587.

46. Ellis SE, Speroff T, Dittus RS, Brown A, Pichert JW, et al. (2004) Diabetes patient education: a meta-analysis and meta-regression. Patient Educ Couns 52: 97-105. [Crossref]

47. Warsi A, Wang PS, Lavalley MP, Avorn J, Solomon DH (2004) Self-management education programs in chronic disease: a systematic review and methodological critique of the literature. Arch. Intern. Med 164: 1641-1649.

48. Norris SL, Lau J, Smith SJ, Schmid CH, Engelgau MM (2002) Self-management education for adults with type 2 diabetes: a meta-analysis of the effect on glycemic control. Diabetes Care 25: 1159-1171. [Crossref]

49. Minet L, Moller S, Vach W, Wagner L, Henriksen JE (2010) Mediating the effect of selfcare management intervention in type 2 diabetes: A meta-analysis of 47 randomised controlled trials. Patient Educ. Couns 80: 29-41.

50. Klein HA, Jackson SM, Street K, Whitacre JC, Klein G (2013) Diabetes selfmanagement education: miles to go. Nurs Res Pract 581012. [Crossref] 
Silva Junior AJ (2019) Effects of an educational program focused on self-care and concurrent physical training on glycemia and drug treatment of patients with diabetes mellitus

51. Figueira ALG, Gomes-Villas Boas LC, Coelho ACM, Foss-Freitas MC, Pace AE (2017) Educational interventions for knowledge on the disease, treatment adherence and control of diabetes mellitus. Rev. Latino-Am. Enfermagem. 2017; 25:e2863.

52. Arsa G, Lima L, Almeida SS, Moreira SR, Campbell CSG, et al. (2009) Type 2 diabetes mellitus: physiological and genetic aspects and the use of physical exercise for diabetes control. Rev. Bras. Cineantropom. Desempenho Hum 11: 103-111.

53. Tokmakidis SP, Zois CE, Volaklis KA, Kotsa K, Touvra AM (2004) The effects of a combined strength and aerobic exercise program on glucose control and insulin action in women with type 2 diabetes. Eur. J. Appl. Physiol 92: 437-442. [Crossref]
54. Monteiro LZ, Fiani CRV, Foss-Freitas MC, Zanetti ML, Foss MC (2010) Decrease in blood pressure, body mass index and glycemia after aerobic training in elderly women with type 2 diabetes. Arq. Bras. Cardiol 95: 563-570. [Crossref]

55. Sousa RAL, Santos NVS, Pardono E (2014) Reducao da glicemia atraves do exercicio resistido de alta intensidade em individuos com diabetes mellitus tipo 2. RBPFEX 8 871-876.

56. Farhat FCLG, Iftoda DM, Santos PH (2007) Interacoes entre Hipoglicemiantes Orais e Alimentos. Saude Rev 9: 57-62.

57. Gimenes HT, Zanetti ML, Otero LM, Teixeira CRS (2006) O conhecimento do paciente diabetico tipo 2 acerca dos antidiabeticos orais. CiEnc. Cuid. Saude 5: 317-325.

Copyright: @2019 Silva Junior AJ. This is an open-access article distributed under the terms of the Creative Commons Attribution License, which permits unrestricted use, distribution, and reproduction in any medium, provided the original author and source are credited. 